\title{
Chinese High-speed Railway (HSR) Construction and Management Model based on the Cooperation of the Government and Enterprises
}

\author{
Chaodong Zhang, Shouwen Ji \\ School of Traffic and Transportation, Beijing Jiaotong University, China
}

\begin{abstract}
Over the past five years, China has witnessed the boom of high-speed railway. more than ten thousand kilometers of high-speed railway has been built. Under the leadership of the government and relevant departments, the efficiency and effectiveness of the model of construction and management have been self-proved by a large number of astonishing achievements. However, currently there are no research documents systematically analyzing the principles and effects of Chinese high-speed railway construction and management model. To fill this gap, we have written this paper to present the background, fundamental principles and effects of this model in depth. Finally, we will conclude by stating the strengths and weaknesses of Chinese model.
\end{abstract}

KEYWORD: High-speed Railway; Construction and Management Model; Chinese Model.

\section{INTRODUCTION}

The high-speed railway (HSR), as a significant national infrastructure for both civil and military aims, has been developing exponentially in recent years in China. The current economic boom in China since 1990s was an advantage for the construction of HSR, including a series of effective and powerful measures to reduce the inflation rate and smoothen the pace of economic development. Meanwhile the government wanted to stimulate consumption by raising investments in infrastructure, which provided a promising opportunity for the development of the HSR, according to the data of the Ministry of Railways of China, the investment is increasing rapidly in recent years.

The Chinese Ministry of Railways claimed that 2.000 billion CNY (approximately equal to 200 billion GBP) would be invested into HSR in the future. Although most of HSR programs are managed and supported by the central government, notably the Chinese Ministry of Railways, local governments and enterprises which come from both China and abroad are also enthusiastic about the HSR programs because of its bright future, positive economic benefits and political interests. Also, thanks to its environmentally-friendly goals and the high quality service of passenger transport, HSR is the most appropriate option in China; especially for middle distance transportation $(200-700 \mathrm{~km})$, HSR plays a positive role in terms of time-saving, moneysaving and reduced emission of greenhouse gases.

As we all know, China is large country with a population of more than 1.4 billion therefore it is crucial for the government to develop appropriate policies to combine the resources of both the Chinese Ministry of Railways and a large number of businesses to develop the HSR programs effectively [1]. However, the HSR is not only a large-scale program, but also a program in a domain where technology is very important and modernized, it includes new materials, power supply technology, control, communication and automation engineering, to complete the project the work of high-tech research companies will be needed. This is a positive feature of the HSR because it will improve the economy as well as provide more opportunities for employment and stimulate the development of hightech industries in China.

\section{CURRENT STATUS OF CONSTRUCTION AND MANAGEMENT MODELS}

Nowadays, the construction project of the HSR in China is one of the largest in the world with a total length of $19,800 \mathrm{~km}$ planned for the future, the planned mapping of the rail network is shown in figure $1[1]$. 


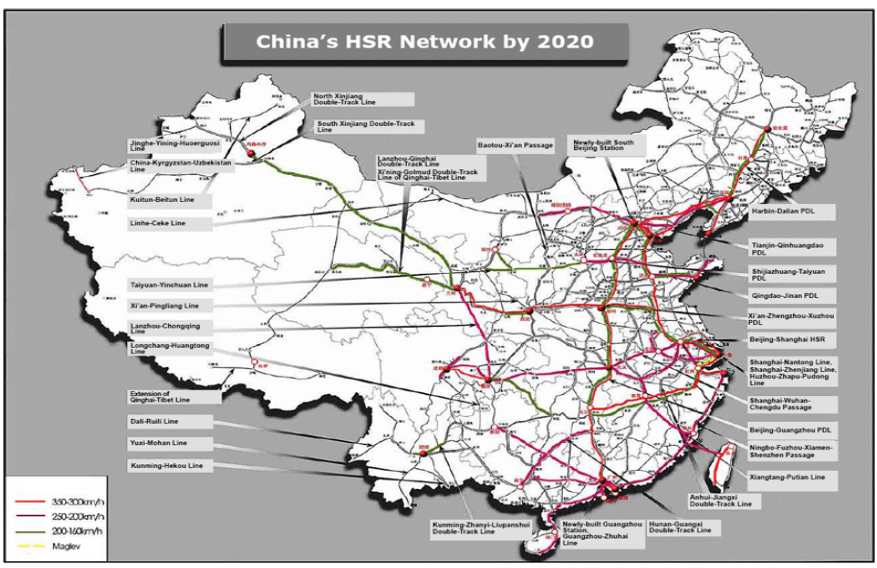

Fig 1. China's HSR Network by 2020

Therefore selecting the optimal and suitable strategic model of construction and management is a key factor for a long-term success. In the UK, the railway reform began in 1983 with the establishment of a national railway administration section in charge of managing and designing all future development and the establishment of several railway enterprises operating railway transportation specifically. The UK stimulated the development of railways and also provided the foundation of the HSR[2], at the same time, Japan organized the Association of Railway Enterprises of Japan (AREJ) in 1980s, which is an important factor for acquiring the most advanced technologies of the HSR, because Japanese scientists and engineers have benefited much from the development of the HSR every year due to the AREJ.

The U.S. is an old railway powerhouse with over 500 companies in the railway construction and management industries. They allowed private funding to join in their railway projects and adopted a series of policies to loosen the control of railway facilities and finance and therefore allow for quick and easy development of the American railways. After reviewing the railway reforms of different countries, it is clear that most of the countries which have advanced the technologies of the HSR and mature HSR networks have put their railway construction into the transportation market as independent entities, some of them as fully independent enterprises, some of them as cooperative enterprises with government. Therefore the relationship between the government and the construction or management firms of HSR can be defined as two models in these developed countries, which are the independent model and united model. However, there is also a third model, which is called state model, according to which all the construction of HSR should be and must be planned and managed by the central government or by state run monopolies. The state model which is based on a planned economy has a large number of disadvantages and cannot meet the needs of the globalization of economies and technology.
Unfortunately, the Chinese government inherited this model from the USSR, for some political purposes and other reasons, the construction of the Chinese HSR is to be done by the government, Chinese government is still sticking to the ideas from the past[3]. Although they have also allowed for some limited foreign investment and technologies, and have invited certain private companies to join in the supply chain of the HSR. Also, the HSR reform is the sixth large-scale speed up plan of China focusing on how to establish and introduce enterprises in accordance with modern economic regulations in the HSR construction and management sector.

\section{CONCEPT OF THE CHINESE MODEL}

China does not belong to any of the three models mentioned above due to the national conditions with Chinese characteristics. On one hand, the Chinese government expects to vigorously develop the HSR with advanced technologies and rich management experiences; on the other hand, they refuse to introduce too much foreign investment and private companies to compete with the state run monopolies.

There are three reasons for this contradiction. First, the HSR is a strategic resource, which relates to national security and geopolitical interest, hence they do not totally trust any other organizations in this field, especially foreign enterprises. Second, the introduction of foreign and private investment would be harmful to groups and people with vested interests, such as state run monopolies, which are likely to be against such an introduction. Third, it is impossible for private enterprises to undertake a construction or management task of the HSR totally independently, because the amount of investment of most of these tasks is more than 10 billion CNY (about 1 billion GBP)[4] and these tasks need several government departments to operate in unity. Therefore it is better to select the model with Chinese characteristics, which can be called the Chinese model.

Specifically, the Chinese model consists of three factors, i.e. government, state run monopolies and private enterprises respectively. The Chinese government, especially the Chinese Ministry of Railways, is responsible for publishing policies, planning and scheduling projects for the HSR and checking the results; state run monopolies, such as China Railway Construction Company (CRCC), undertake the main tasks, reap $90 \%-95 \%$ profits on a project for the HSR.

These tasks include locomotive manufacturing, track laying, communication network construction and power grid construction, while the private enterprises just take on some simple and marginal tasks which just make up 5\%-10\% profits of a whole 
project, e.g. food and drink preparing, cleaning, supporting facility construction, ticket service[5] etc.

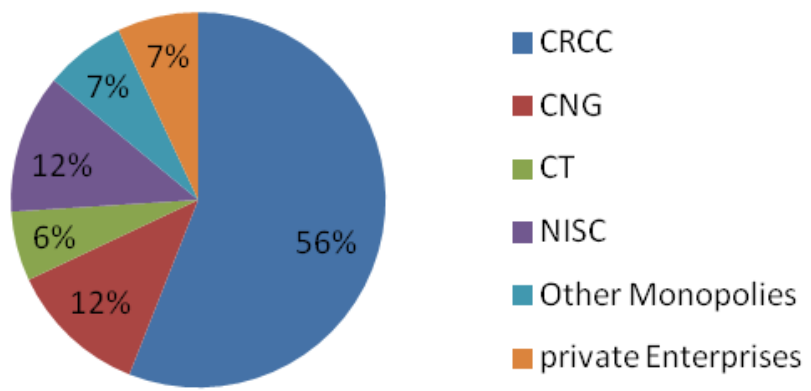

Fig 2. Average percentage of profits of Beijing-Shanghai HSR[7] ${ }^{1}$

An example is represented by the profits of the Beijing-Shanghai HSR in fig.2 [6].

From the chart above, we can see that the Chinese model is a model where the project is mainly administrated by the government and state run companies, whereas it also needs a fraction of private enterprises to supply marginal service for the whole project of HSR.

\section{IMPACTS OF POLICY FACTORS OF THE CHINESE MODEL FOR HSR}

Because most parts of the HSR projects are administrated by the government and state run monopolies, relevant policy factors are important guidelines for the HSR. The Chinese government has published about 1300 legal articles to support the HSR construction, which cover investment attracting, patent protection, and design Standards for the HSR industry. According to these legal articles, we can see the strong determination of Chinese authority. As a result, more and more people and enterprises consider the HSR as a promising project and get involved in this field.

Compared to 2007 and before, the College Entrance Examination ( also known as Gaokao) scores of those colleges for HSR in China have increased by 20\%-30\%[8]; design patents for HSR technologies have risen by 60\%[9] and a number of relevant enterprises of HSR have grown by more than five times, reaching about 4600[10], in many different domains. Meanwhile, there are many attractive policies, which lead financial groups to pay close attention to HSR construction, even to do a precise investigation on HSR projects becomes more and more.

1 CRCC $=$ China Railway Construction Company; CNG=China National Grid; CT=China Telecom; NISC=National Iron and Steel Company.
On the other hand, a growing number of scientists, engineers and sociologists are trying their best to make contributions to the HSR, because the new law of patent protection has built a positive platform for them to perform on. Also, design standards for the HSR industry offer a guideline for construction and manipulation of the HSR. To some extent they improve the engineering quality of HSR construction, management and reduce accidents which encourages more people to take high-speed trains during their trips and stimulates the development of the HSR industry indirectly. Because China is a country under the rule of law, the industrial restructuring and reform of HSR has to be based on legislation. Thus, it is an effective way to change the distribution of the benefits of the HSR by legislation, which will have a positive impact on the development of the HSR, and also encourage people to support HSR constructions and researches.

\section{EVALUATION OF THE CHINESE MODEL}

According to the current state of HSR in China, the Chinese model would be the optimal strategy of railway construction and management, with the constructions of infrastructures and HSR operations managed and maintained as a single entity. As for the financial problem, most of the projects of the HSR require several billion CNY, which represents a major obstacle for private enterprises that cannot raise this type of capital, hence it is impossible to guarantee the engineering quality and financial risk. For this reason, it is important and safe to raise a large fund and monitor the project by government and state run monopolies. This leads to more effective and reliable maintenance work of HSR, thanks to their strong financial and technical supports.

Another aspect is represented by the construction and management of the HSR, which involves dozens of high-tech areas, including materials manufacturing, electrical power engineering, telecommunication engineering etc. It is burdensome for private enterprises to mobilize these areas simultaneously; furthermore, the HSR is a strategic resource and before its construction, military and political factors should be taken into consideration. Therefore, most projects of the HSR are to be administrated by government and state run monopolies. However, there are still many private enterprises involved in such a large project, which helps government and state run monopolies to improve marginal constructions and services and shares the pressures of monopolies. What private enterprises have done is also remarkable in the history of HSR development.

However, there are some disadvantages with the Chinese model. 
First, according to Chinese policy and law, the government and state run monopolies are not responsible for funding. Funding for construction and management of HSR come from national debt as shown in fig 3[11].

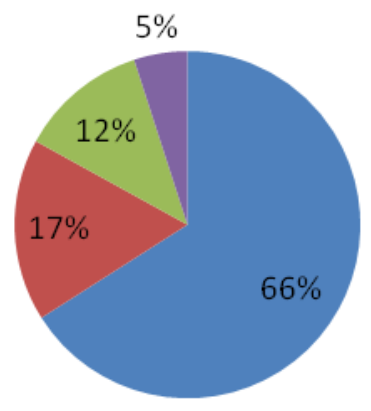

China Railway
Investment Corp
National Social
Security fund
Local Government
Railway fund
Others

Fig.3. Beijing-Shanghai HSR ownership

Second, the Chinese model is not based on the modern market economy, which may lead to an unfair and monotonous construction result. It is reported that plenty of investment has been bribed and diverted, because of the lack of improved accounting review system within these businesses.

\section{CONCLUSION}

After the analysis and evaluation, it is clear that the Chinese HSR construction and management must start a comprehensive reform in order to meet the needs of the future market economy and rapid development of technology. Although the Chinese model has played an important role in the past ten years, and has made a large contribution to HSR in China, it is falling into obsolete now.

Along with the modern high-tech development, the Chinese model reveals its essential disadvantages, such as the lack of creativeness and monitoring.

Fortunately, a series of recent reforms of the HSR shows that it is an irresistible trend in building an improved corporation system among the government, state run monopolies and private enterprises.

\section{ACKNOWLEDGEMENT}

The paper is supported by the science and technology project "Guidelines for urban public traffic network optimization technology in Guangxi Province".

\section{REFERENCES}

[1] Yang, Y., Sun, M. (2010). China railway restructuring: Analysis on effective competition. Logistics Systems and Intelligent Management, 2010 International Conference (p. 677-681).

[2] Chen, Z., Ho, T. and Mao, B. (2010). Feasibility of open markets for main line railways in China, in Railway Traction Systems (RTS 2010), IET Conference (p. 13-15).

[3] Li, W. (2008). Research on the Quantitative Relationship between China's Railway Transportation Industry and National Economic Development. Future Information Technology and Management Engineering, 2008. FITME '08. International Seminar (p.445-449).

[4] Sun, M., Zhang, Q. (2009). China Railways Restructuring: Review and Evaluation. Electronic Commerce and Business Intelligence, 2009. ECBI 2009. International Conference (p. 225-229).

[5] Si, Y., Chen, J., Zhou, Y. and Yao, W. (2011). A case study on the innovation and production of China Railway High-speed: In the perspective of complex product systems innovation. Technology Management in the Energy Smart World (PICMET), 2011 Proceedings of PICMET '11 (p. 1-7).

[6] Ma, H., Zhao, X. and Dang, J. (2009). An autonomous integration model based on flexible service for China Railway Heterogeneous Information System. Industrial Electronics and Applications, 2009. ICIEA 2009. 4th IEEE Conference (p. 25-27).

[7] Han, Z., Liu, S., Gao, S. and Bo, Z. (2010). Protection scheme for China high-speed railway. Developments in Power System Protection (DPSP 2010). Managing the Change, 10th IET International Conference (p. 1-5).

[8] Wu, W., Wang, J. (2011). China railway construction project financing model. E -Business and E -Government (ICEE), 2011 International Conference (p. 1-8).

[9] Kang, S., Li, J., Liu M. and Zhu, X. (2011). Prediction based on support vector machine for travel choice of highspeed railway passenger in China. Management Science and Engineering (ICMSE), 2011 International Conference (p. 28-33).

[10] Chen, X., Li, J. and Li, X. (2008). Coordinated development analysis on economic efficiency and technical level of railway transportation industry in China. Service Operations and Logistics, and Informatics, 2008. IEEE/SOLI 2008. IEEE International Conference (p. 1876-1879).

[11] W, S., Li, X. (2011). Discussion on status and improvement measures about law and regulations of railway construction in China. Management Science and Industrial Engineering (MSIE), 2011 International Conference (p. 770-774). 